\title{
Sulfasalazine Versus Meloxcam in Rheumatoid Arthritis
}

Rawan M AL Dabbas *, Hazar M Hijazeen, Alaa M Mrayat, Qais M Bnayan, Mohammad S AL Jariri

The Royal Medical Services. Amman/Jordan

DOI: $\underline{10.36347 / \text { sajp.2020.v09i05.002 }}$

| Received: 12.02.2020 | Accepted: 19.02.2020 | Published: 30.05.2020

*Corresponding author: Rawan M AL Dabbas

Abstract

Original Research Article

Background: Sulfasalazine is recently considered to be a valuable drug in the treatment of rheumatoid arthritis (RA) The objective of this study is to examine the efficacy and toxicity of sulfasalazine alone or in combination with meloxicam in the treatment of moderate to severe RA. Methods: This study is a 3-month retrospective observational study. The study was carried out in the Royal Rehabilitation Center at the Royal Medical Services (RMS) in Jordan/Amman. Patients with moderate to severe RA (classified according to the American College of Rheumatology (ACR) criteria) will be randomly allocated into two groups: Group I: receiving Sulfasalazine 500mg twice daily orally. Group II: receiving Sulfasalazine plus Meloxicam $15 \mathrm{mg}$ tablets once daily. Clinical assessment will include pain assessment (using 11-point numerical rating scale), laboratory results and monitoring of undesirable effects and radiological evaluation. Data will be accessed through revision of patient's medical profiles and Hakeem data base. Results: Statistically significant reduction in all scores of the measured clinical parameters at baseline and after 12 weeks of administration of sulfasalazine in both groups by the end of 12 weeks treatment duration $(\mathrm{P}<0.05)$. The average of total progress in the clinical and laboratory readings revealed that sulfasalazine alone or when combined with meloxicam lead to around total proportion of progress ranging from $24.5 \%$ to $28.4 \%$ after 12 weeks of administration of anti-rheumatic drugs. Sulfasalazine had led to a reduction symptoms severity by $44.8 \%$. This reduction is augmented to $66.2 \%$ when sulfasalazine is combined with meloxicam. Conclusion: Sulfasalazine administration for 12 weeks caused significant improvement in clinical parameters, including the number of swollen joints and the level joint pain. Meloxicam when administered with sulfasalazine, produce improvement in the effect noted by sulfasalazine. Meloxicam should be favorably given to individuals with higher level of pain and RA activity and those who had less rate of response to other NSAIDs.

Keywords: Sulfasalazine, rheumatoid arthritis (RA), Royal Medical Services (RMS), Rheumatology.

Copyright @ 2020: This is an open-access article distributed under the terms of the Creative Commons Attribution license which permits unrestricted use, distribution, and reproduction in any medium for non-commercial use (NonCommercial, or CC-BY-NC) provided the original author and source are credited.

\section{INTRODUCTION}

Rheumatoid arthritis (RA) is a systemic, multipart, and heterogeneous autoimmune disease (AD) that is described by the particular injury of the covering of the synovial joints and can lead to advanced disablement and early mortality. The RA occurrence fluctuates between $1 \%$ and $1.5 \%$ of the populace, and RA disturbs mainly females and adults in 30 s with a highest in the fifth period of age. RA is classically grouped into 2 classes titled "seropositive" and "seronegative" illness, with seropositivity has been described as the existence of serum rises of the autoantibodies "rheumatoid factor"(RF) and the more lately defined antibodies to "citrullinated protein/peptide antigens" (ACPAs) [1].

RA is a multifactorial illness in which there is an inter-relation between susceptibility factors and environmental reasons which result in the occurrence of the disease. Of these, the most powerful relations have been observed with female gender, past family history of RA, the genetic influence the "shared epitope" and with cigarette smoking, alcohol and coffee consumption. Similarly, new concern in mucosal inflammation and infectious factors as causes of RA [2].

The key picture of RA is insistent symmetric polyarthritis (synovitis) that harm the hands and feet, even though any joint lined by a synovial membrane may be affected. The clinical presentation of RA includes pain on motion, tenderness, deformity, warm, swollen joints, joint stiffness that is usually worse in the mornings and after inactivity, limitation of motion, malaise, fatigue, fever and loss of appetite (Figure-1) [3]. 


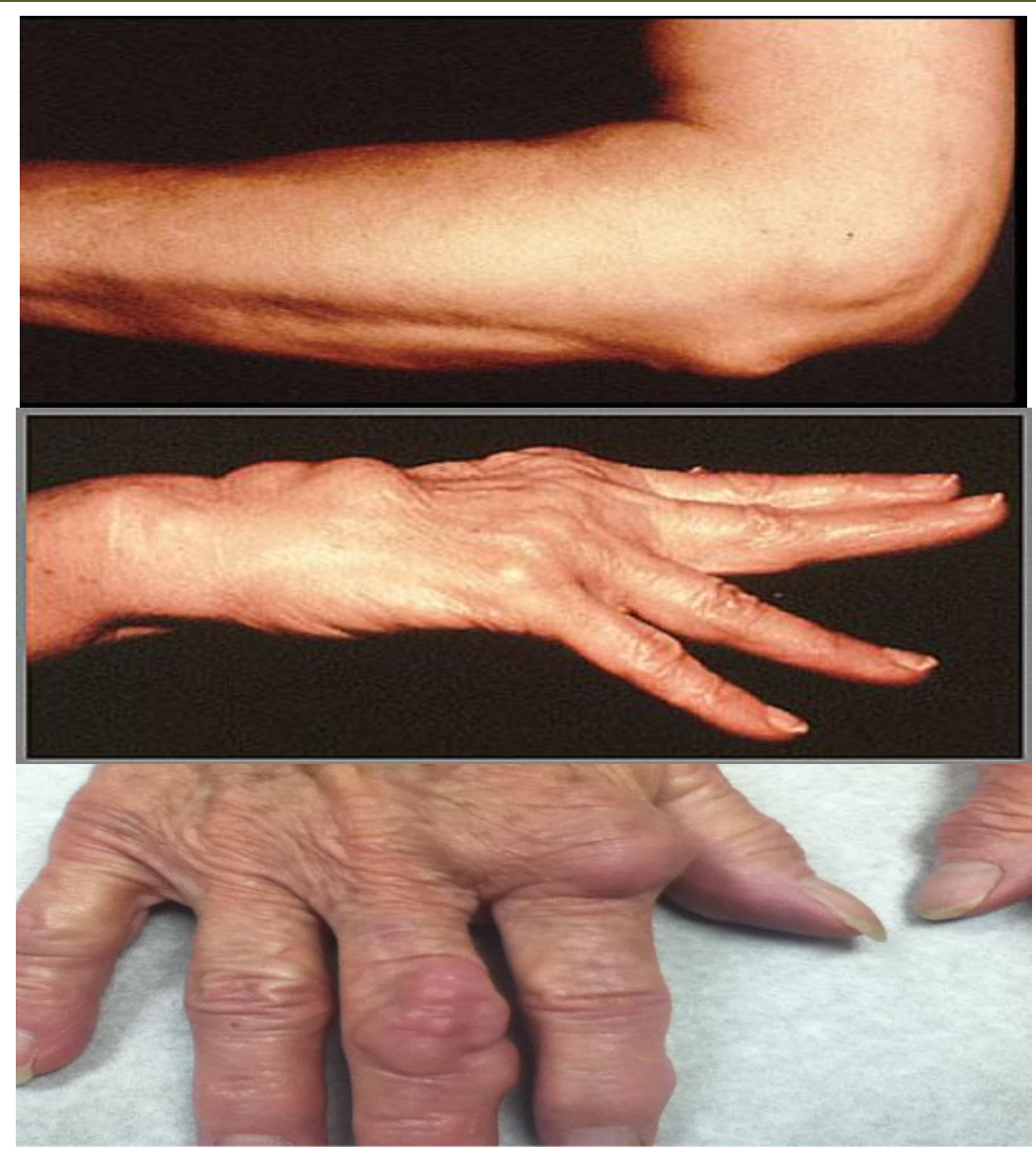

Fig-1: Deformity in RA

Regarding the diagnosis of RA, diagnosis is performed by means of clinical, laboratory, and imaging techniques. Possibly beneficial laboratory tests in doubted RA include the following: ESR, CRP, CBC, RF assay, "Antinuclear antibody assay", "Anti-cyclic citrullinated peptide" and "anti-mutated citrullinated vimentin assays". While possibly valuable imaging techniques include the following: $\mathrm{X}$ - ray radiography including upper and lower extremities including the joints, MRI, and ultrasonography of joints.

There is presently no cure for RA, the management approach purposes to accelerate diagnosis and quickly attain a low disease activity situation [4]. Five chief types of medications are now used: "analgesics:, "non-steroidal anti-inflammatories" (NSAIDs), "glucocorticoids", "nonbiologic" and "biologic disease-modifying antirheumatic drugs". Methotrexate, sulfasalazine, leflunomide and hydroxychloroquine (HCQ) are the usually used DMARDs. Application of non-steroidal antiinflammatory drugs (NSAIDs) and systemic corticosteroids have been approved to be efficient in dismissing painfulness, but do not settle down RA progression. In the last two decades, the efficiency of DMARDs has taken more consideration since they can capably reduce RA activity and significantly lessening and/or interrupt joint abnormality [5].
DMARDs must be used in all individuals with RA. The administration of DMARDs should be taken in consideration for all patients with indistinguishable arthritis and in patients with positive rheumatoid factors (RFs) test [6].

In the management of RA, NSAIDs are administered mostly on a transient base to relieve joint swelling, stiffness, and pain till the DMARDs produce its effect, in addition to their use in RA relapse. There are at least 15 various NSAIDs which are administered such as diclofenac, indomethacin, naproxen, celecoxib and meloxicam [7].

Sulfasalazine is a non-biologic DMARD that is used in the management of RA as it has antiinflammatory and antimicrobial effect. The duration before any effect is noted is approximately 4 weeks-3 months [8].

Biologic tumor necrosis factor (TNF)-
inhibiting DMARDs include "Etanercept",
"Infliximab", "Adalimumab", "Certolizumab" and
"Golimumab". Biologic non-TNF DMARDs includes
"Rituximab, Anakinra, Abatacept, Tocilizumab,
Sarilumab, Tofacitinib, Baricitinib and Upadacitinib"
[9].


The aim of the current study was to explore the effectiveness and toxicity of sulfasalazine alone or in combination with meloxicam in the treatment of moderate to severe RA.

\section{Patients and Method}

This study was a 3-month retrospective observational study. The study was carried out in the Royal Rehabilitation Center at the Royal Medical Services (RMS) in Jordan/Amman. Patients with moderate to severe RA (classified according to the American College of Rheumatology (ACR) criteria) were randomly allocated into two groups: Group I: receiving Sulfasalazine $500 \mathrm{mg}$ twice daily orally. Group II: receiving Sulfasalazine plus Meloxicam 15 $\mathrm{mg}$ tablets once daily. Clinical assessment included pain assessment (using 11-point numerical rating scale), laboratory results and monitoring of undesirable effects and radiological evaluation. Data was accessed through revision of patient's medical profiles and Hakeem data base. The study design was approved by the Ethical Committee at the Royal Medical Services (RMS).
Statistical Package for the Social Sciences (SPSS) version 24 was used for analysis. Baseline characteristics and demographic data were analyzed using descriptive statistics and 2-sided t tests for continuous variables and the Fisher exact test for categorical variables. Clinical outcome end points were analyzed using 2-sided $\mathrm{t}$ tests. When comparing continuous variables between the two study groups ANOVA (repeated measure) test was used. The significance level was set at 0.05 .

\section{RESULTS}

Sixty two patients with moderate to severe RA were recruited to participate in the study and allocated into 2 groups: Group1: Sulfasalazine (500mg oral tablets twice daily, $\mathrm{N}=31$ patients), and Group 2: Sulfasalazine plus meloxicam $(15 \mathrm{mg}$ oral tablet once daily, $\mathrm{N}=31$ patients). The treatment course for the study sample was 3 months. Baseline characteristics of the 62 patients, according to study group regarding age, gender, duration of disease and number of swollen joints are presented in Table-1.

Table-1

\begin{tabular}{|l|l|l|l|}
\hline Parameter & Group 1 $(\mathbf{n = 3 1})$ & Group 2 $(\mathbf{n = 3 1})$ & $\boldsymbol{P}$ value \\
\hline Mean age $( \pm$ SD) & $55.8 \pm 17.7$ & $58.9 \pm 16.8$ & 0.91 \\
\hline Female no\% & $16(51.6) 0.38$ & $17(54.8)$ & 0.41 \\
\hline Mean weight $(\mathrm{kg})$ & $76.8(11.6)$ & $77.1(12.9)$ & 0.78 \\
\hline Number of swollen joints (Mean \pm SD) $)$ & $22.6 \pm 10.1$ & $23.9 \pm 9.9$ & 0.633 \\
\hline Duration of disease (years) & $13.6 \pm 4.1$ & $12.7 \pm 3.9$ & 0.34 \\
\hline
\end{tabular}

\section{Effects of sulfasalazine on clinical and hematological parameters}

Results revealed that there was a statistically significant reduction in all scores of the measured clinical parameters at baseline and after 12 weeks of administration of sulfasalazine in both groups, Furthermore, regarding hematological parameter there was statistically significant changes in ESR and CRP in the same treatment group and in comparison between the 2 study groups (Table-2). The average of total progress in the clinical and laboratory readings revealed that sulfasalazine alone or when combined with meloxicam lead to around total proportion of progress ranging from $24.5 \%$ to $28.4 \%$ after 12 weeks of administration of anti-rheumatic drugs. Sulfasalazine had led to a reduction symptoms severity by $44.8 \%$. This reduction is augmented to $66.2 \%$ when sulfasalazine is combined with meloxicam.

Table-2: The effects of treatment on clinical and hematological parameters in patients with RA

\begin{tabular}{|c|c|c|c|c|c|c|c|}
\hline & Group $1(\mathrm{~N}=$ & & & Group $2(\mathbf{N}$ & & & \\
\hline Clinical Parameter & At Baseline & $\begin{array}{l}\text { After } 12 \text { weeks } \\
\text { of treatment }\end{array}$ & $\begin{array}{l}\mathrm{P} \text { - } \\
\text { value }\end{array}$ & At Baseline & $\begin{array}{l}\text { After } 12 \text { weeks } \\
\text { of treatment }\end{array}$ & $\begin{array}{l}\text { P- } \\
\text { value }\end{array}$ & $\begin{array}{l}\text { P-value } \\
\text { between the } 2 \\
\text { study groups }\end{array}$ \\
\hline $\begin{array}{l}\text { Joint pain } \\
\text { (severity) }\end{array}$ & $3.32 \pm 0.7$ & $1.34 \pm 0.54$ & 0.087 & $3.45 \pm 0.81$ & $1.11 \pm 0.79$ & 0.032 & 0.042 \\
\hline Morning stiffness & $24.66 \pm 12.8$ & $21.8 \pm 12.41$ & 0.041 & $25.1 \pm 11.9$ & $20.09 \pm 9.8$ & 0.024 & 0.032 \\
\hline $\begin{array}{l}\text { No of } \\
\text { swollen joints }\end{array}$ & $3.99 \pm 2.1$ & $3.13 \pm 0.99$ & 0.08 & $4.18 \pm 3.4$ & $2.21 \pm 3.4$ & 0.043 & 0.024 \\
\hline $\begin{array}{l}\text { No of the } \\
\text { tender joints }\end{array}$ & $7.21 \pm 3.13$ & $5.43 \pm 2.89$ & 0.049 & $8.11 \pm 2.94$ & $5.89 \pm 1.89$ & 0.038 & 0.037 \\
\hline $\begin{array}{l}\text { Patient global } \\
\text { Assessment }\end{array}$ & $3.67 \pm 0.89$ & $2.65 \pm 0.71$ & 0.34 & $4.01 \pm 0.74$ & $2.15 \pm 0.51$ & 0.047 & 0.042 \\
\hline $\begin{array}{ll}\begin{array}{l}\text { Physician } \\
\text { assessment }\end{array} & \text { global } \\
\end{array}$ & $5.1 \pm 0.79$ & $3.5 \pm 0.65$ & 0.028 & $4.9 \pm 0.64$ & $3.01 \pm 0.41$ & 0.021 & 0.0311 \\
\hline Hemoglobin $(\mathrm{gm} / \mathrm{dl})$ & $12.09 \pm 0.99$ & $12.34 \pm 0.81$ & 0.87 & $12.8 \pm 0.85$ & $12.1 \pm 0.56$ & 0.71 & 0.85 \\
\hline ESR (mm/hr) & $34.8 \pm 16.6$ & $26.7 \pm 12.8$ & 0.042 & $33.9 \pm 18.9$ & $31.4 \pm 15.98$ & 0.036 & 0.038 \\
\hline Platelet count & $311 \pm 85.8$ & $287 \pm 81$ & 0.65 & $344 \pm 88$ & $309 \pm 76$ & 0.59 & 0.71 \\
\hline CRP mg/liter & 41.2653 .2 & $28.24 \pm 12.1$ & 0.031 & $44.6 \pm 17.6$ & $27.2 \pm 13.7$ & 0.031 & 0.028 \\
\hline
\end{tabular}




\section{Treatment Toxicity}

Eight $(26 \%)$ of individuals treated with sulfasalazine alone and $11(35 \%)$ treated with combination of sulfasalazine and meloxicam addressed side effects, respectively. Gastrointestinal effects, headache, dizziness and rash were the most reported side effects in both study groups.

\section{DISCUSSION}

Management of RA is focused on resolution of symptoms, treat inflammation (chronic synovitis) and re-establishment of ability in inflamed joints. This can be attained by medications, relaxation, rehabilitation or performing surgical procedures [10]. The administration of DMARDs must be implemented in all individuals with clinical features of active disease. Most of physicians consider that individuals with RA must be managed with DMARDs before the RA progress to advanced stages [11]. If DMARDs are administered before disease progression, this will result in terminating joint ache, and swelling. Also will DMARDs early use decrease the systemic symptoms, ESR, and RF level, which in turn lead to reduction in the rate of radiological advance of RA. Sulfasalazine is extensively administered in the management of RA. Decrease in pain severity, swelling of the joints, ESR and CRP will be noted after 10-12 weeks of therapy [12]. Throughout the 3 month period of sulfasalazine administration in the present study, it caused a total progress of $28 \%$. Nevertheless, when sulfasalazine therapeutic outcome effect is compared with the therapeutic outcome of methotrexate (MTX) [15]. MTX showed more efficacy in regard to the pain level, number of swollen joints and radiological changes. Administration of meloxicam with sulfasalazine had significantly improved the overall response to sulfasalazine in regard to joint pain severity, morning stiffness, number of swollen joints, and the number of the tender joints. In contrary, combination of MTX with other NSAIDs (diclofenac) was found with no significant improvement when compared to sulfasalazine alone. Our findings showed clear evidence that early administration of sulfasalazine with meloxicam significantly reduces the degree of radiological involvement in individuals with RA [13]. The outcomes of the current study are consistent with those of double blind comparative trials that revealed that meloxicam is more efficient in managing the active inflammation of active RA when combined with sulfasalazine with a superior GI tolerability profile than other NSAIDs [14]. In spite of our optimistic outcomes, sulfasalazine monotherapy is not an ideal method for attaining long-term stability in individuals with early RA [16].

\section{CONCLUSION}

Sulfasalazine administration for 12 weeks caused significant improvement in clinical parameters, including the number of swollen joints and the level joint pain. Meloxicam when administered with sulfasalazine, produce improvement in the effect noted by sulfasalazine. Meloxicam should be favorably given to individuals with higher level of pain and RA activity and those who had less rate of response to other NSAIDs.

\section{REFERENCES}

1. Kitada A, Min C, Kataoka Y, Kaneshita S, Suda M, Takasugi K, Ohara Y, Rokutanda R, Shimizu H, Tsuda T, Kishimoto M. AB0262 Verification of Antibacterial Effect of Sulfasalazine in Rheumatoid Arthritis Patients.

2. Bharat S, Srivastava B, Singh P, Bhardwaj R, Gaur S. Efficacy of combination therapy of methotrexate with hydroxychloroquine or sulfasalazine in rheumatoid arthritis patients in Kumaon region: a comparative study. Journal of Evolution of Medical and Dental Sciences. 2016 Jun 27;5(51):3403-7.

3. Narayan N, Rigby S, Carlucci F. Sulfasalazine induced immune thrombocytopenia in a patient with rheumatoid arthritis. Clinical rheumatology. 2017 Feb 1;36(2):477-9.

4. Chen J, Lin S, Liu C. Sulfasalazine for ankylosing spondylitis. Cochrane Database of Systematic Reviews. 2014(11).

5. Grijalva CG, Chung CP, Arbogast PG, Stein CM, Mitchel Jr EF, Griffin MR. Assessment of adherence to and persistence on disease-modifying antirheumatic drugs (DMARDs) in patients with rheumatoid arthritis. Medical care. 2007 Oct 1:S66-76.

6. Smolen JS, Aletaha D, Keystone E. Superior efficacy of combination therapy for rheumatoid arthritis: fact or fiction?. Arthritis \& Rheumatism: Official Journal of the American College of Rheumatology. 2005 Oct;52(10):2975-83.

7. Scott DL, Smolen JS, Kalden JR, Van de Putte LB, Larsen A, Kvien TK, Schattenkirchner M, Nash P, Oed C, Loew-Friedrich I. Treatment of active rheumatoid arthritis with leflunomide: two year follow up of a double blind, placebo controlled trial versus sulfasalazine. Annals of the rheumatic diseases. 2001 Oct 1;60(10):913-23.

8. Combe B, Codreanu C, Fiocco U, Gaubitz M, Geusens PP, Kvien TK, Pavelka K, Sambrook PN, Smolen JS, Wajdula J, Fatenejad S. Etanercept and sulfasalazine, alone and combined, in patients with active rheumatoid arthritis despite receiving sulfasalazine: a double-blind comparison. Annals of the rheumatic diseases. 2006 Oct 1;65(10):1357-62.

9. Tanaka E, Taniguchi A, Urano W, Nakajima H, Matsuda Y, Kitamura Y, Saito M, Yamanaka H, Saito T, Kamatani N. Adverse effects of sulfasalazine in patients with rheumatoid arthritis are associated with diplotype configuration at the $\mathrm{N}$-acetyltransferase 2 gene. The Journal of rheumatology. 2002 Dec 1;29(12):2492- 
10. Brooks CD. Sulfasalazine for the management of juvenile rheumatoid arthritis. The Journal of rheumatology. 2001 Apr 1;28(4):845-53.

11. Plosker GL, Croom KF. Sulfasalazine. Drugs. 2005 Sep 1;65(13):1825-49.

12. Capell HA, Madhok R, Porter DR, Munro RA, McInnes IB, Hunter JA, Steven M, Zoma A, Morrison E, Sambrook M, Poon FW. Combination therapy with sulfasalazine and methotrexate is more effective than either drug alone in patients with rheumatoid arthritis with a suboptimal response to sulfasalazine: results from the doubleblind placebo-controlled MASCOT study. Annals of the rheumatic diseases. 2007 Feb 1;66(2):23541.

13. Jansen G, van der Heijden J, Oerlemans R, Lems WF, Ifergan I, Scheper RJ, Assaraf YG, Dijkmans BA. Sulfasalazine is a potent inhibitor of the reduced folate carrier: implications for combination therapies with methotrexate in rheumatoid arthritis. Arthritis \& Rheumatism:
Official Journal of the American College of Rheumatology. 2004 Jul;50(7):2130-9.

14. Strand V, Scott DL, Emery P, Kalden JR, Smolen JS, Cannon GW, Tugwell P, Crawford B. Physical function and health related quality of life: analysis of 2-year data from randomized, controlled studies of leflunomide, sulfasalazine, or methotrexate in patients with active rheumatoid arthritis. The Journal of Rheumatology. 2005 Apr 1;32(4):590601.

15. Mease PJ, Clauw DJ, Gendreau RM, Rao SG, Kranzler J, Chen W, Palmer RH. The efficacy and safety of milnacipran for treatment of fibromyalgia a randomized, double-blind, placebo-controlled trial. The Journal of rheumatology. 2009 Feb 1;36(2):398-409.

16. Pollard L, Choy EH, Scott DL. The consequences of rheumatoid arthritis: quality of life measures in the individual patient. Clinical and experimental rheumatology. 2005 Sep 1;23(5):S43. 